\title{
Biosorption of Mercury onto Protonated Pistachio Hull Wastes - Effect of Variables and Kinetic Experiments
}

\author{
N. Rajamohan
}

\begin{abstract}
Batch parametric experiments were performed to study the applicability of protonated pistachio hull waste as a sorbent with respect to the effect of $\mathrm{pH}$ of the solution, initial metal concentration, sorbent dosage and temperature on the metal removal efficiency. Optimum conditions for mercury removal were found to be $\mathrm{pH}$ 7.0 and adsorbent dose - 1.0 $\mathrm{g} / \mathrm{L}$.The metal uptake increased with increase in the initial concentration of the metal. The sorption process was identified as endothermic in nature favouring use of high temperature. The kinetic studies revealed that pseudo-second order model fitted well and the constants were determined. The pseudo-second order rate constant and maximum uptake capacity were found as $1.99 \times 10^{-3} \mathrm{~g} \mathrm{mg}^{-1} \mathrm{~min}^{-1}$ and $48.78 \mathrm{mg} \mathrm{g}^{-1}$ with $50 \mathrm{mg} \mathrm{L}^{-1}$ metal concentration. Thermodynamic studies were conducted and the activation energy for the adsorption of mercury onto was found to be $10.26 \mathrm{KJ} / \mathrm{mol}$.
\end{abstract}

Index Terms-Absorbent, metal removal, pistachio hull waste.

\section{INTRODUCTION}

Rapid development of metal plating industries, mining activities, tanneries, fertiliser and paper industries has led to the direct or indirect release of heavy metals into the environment. The treatment of heavy metals is of special concern due to their recalcitrance and persistence in the environment [1]. The harmful heavy metals of immediate priority are identified as nickel, mercury, copper and zinc. Mercury is reported to be a neurotoxin and can cause irreparable damage to the central nervous system. High mercury dosages can cause impairment of pulmonary and kidney function, chest pain and dyspnoea [2]. Faced with stringent regulations, treatment of heavy metal treatment is of utmost importance. Numerous methods are practised in order to treat the metal contaminated effluent such as precipitation, ion exchange, electrolysis, separation by membrane, adsorption, etc. The method of wastewater treatment is selected according to the concentration of the waste and the cost of treatment [3]-[5].

Adsorption is one of the more popular methods for the removal of metals ions from the aqueous solutions. Adsorption is a physical phenomenon where no chemical reaction takes place. It is now recognized as an effective and economic method for heavy metal wastewater treatment. The adsorption process offers flexibility in design and operation and in many cases will produce high-quality treated effluent [6]. Activated carbons, because of their high surface area, micro porous character and the chemical nature of surface,

Manuscript received November 23, 2013; revised February 25, 2014

N. Rajamohan is with the Department of Chemical Engineering, Faculty of Engineering, Sohar University, Sohar, Oman (e-mail: Rnatarajan@soharuni.edu.om). have been a popular adsorbent for the removal of heavy metals from aqueous solutions. Due to high cost and losses of activated carbon in the application processes, there is growing interest in using low-cost alternative materials including clays, zeolites, coal, fly ash, peat, siderite, agricultural waste, charcoal. Agricultural wastes and industrial by products offer a good choice and has many advantages like simple technique; requires little processing; good adsorption capacity; selective adsorption of heavy metals; low cost; free availability and easy regeneration [7]. Studies on the efficiency of sawdust in the removal of $\mathrm{Cu}^{2+}$ and $\mathrm{Zn}^{2+}$ ions were conducted [8]. Removal of copper by dehydrated wheat bran has been reported [9].Many studies have been conducted on the potential of industrial by-products for metal removal, such as red mud, calcined phosphate and clarified sludge. Biosorption is being demonstrated as a useful alternative to conventional systems for the removal of toxic metals from industrial effluents. Adsorption of copper, zinc, lead and cadmium onto the carbon produced from nutshells of walnut, hazelnut, pistachio, almond, and apricot stone has been investigated [10]. In this background, this research study is aimed at utilisation of protonated pistachio hull waste as an alternative biosorbent for the removal of mercury from its aqueous solution. Effect of process variables like $\mathrm{pH}$, biosorbent dose, initial metal concentration and temperature on the metal remove efficiency was studied. The mechanism of sorption was investigated through kinetic experiments. Thermodynamic studies were performed to estimate the activation energy.

\section{MATERIALS AND METHODS}

\section{A. Pistachio Hulls Waste-Sorbent Preparation}

Pistachio Hulls Waste (PHW) were obtained from nuts market. The hulls were washed using the tap water followed by distilled water in order to remove the impurities. Hull waste was dried in sunny ambient air for 3 days and subsequently crushed in order to reduce the size of the particles. The reduced size was ground using a high speed grinder and sieved, where the final size of PHW between $0.063-0.106 \mathrm{~mm}$. Finely powdered adsorbent is acid activated by soaking the PHW in $0.1 \mathrm{M} \mathrm{HCl}$ for 24 hours in order to protonate the surface and was dried at $35^{\circ} \mathrm{C}$ overnight. A weight loss of approximately $11 \%$ was observed. The acid activated adsorbent is termed as "Protonated Pistachio Hull Waste (PPHW)".

\section{B. Parametric Studies}

The stock solutions $(1000 \mathrm{mg} / \mathrm{L})$ of $\mathrm{Hg}^{2+}$ was prepared by dissolving $\mathrm{Hg}\left(\mathrm{NO}_{3}\right)_{2} .1 / 2 \mathrm{H}_{2} \mathrm{O}$ in double distilled water and 
stored in refrigerator. To study the effect of parameters such as adsorbent dosage, $\mathrm{pH}$, initial concentration and the temperature for the removal of metal, batch experiments were carried out in a temperature controlled shaker at room temperature. The adsorption isotherm experiment was carried out by agitating $100 \mathrm{~mL}$ metal solutions of various concentrations. After agitation, the mercury solutions were separated from the adsorbent by filtration using Whatmann no.4 filter paper. Metal concentration in the supernatant solutions was measured using an atomic absorption spectrophotometer. The effect of initial $\mathrm{pH}$ on metal removal was studied over a $\mathrm{pH}$ range of (2.0-9.0). The initial $\mathrm{pH}$ of the metal solution was adjusted by the addition of $0.5 \mathrm{M}$ solution of $\mathrm{H}_{2} \mathrm{SO}_{4}$ or $\mathrm{NaOH}$. To find the optimum amount of adsorbent per unit mass of the adsorbate, the metal solution $(100 \mathrm{~mL})$ was contacted with different amounts of PPHW till equilibrium was reached. The sorbent dosages were studied in range 1.0-7.0 $\mathrm{g} / \mathrm{L}$. The effect of temperature on the adsorption characteristics was studied by determining the adsorption isotherms at 303,313 , and $323 \mathrm{~K}$ with a fixed metal concentration and dosage. The metal removal percentage and uptake were calculated using the following relationships:

$$
\begin{gathered}
\% \text { Removal efficiency }(R E \%)=\left[\frac{C_{\mathrm{o}}-C_{e}}{C_{\mathrm{o}}}\right] \times 100 \\
\text { Metal uptake, } q_{e}=\frac{\left[\left(C_{\mathrm{o}}-C e\right) \times V\right]}{m}
\end{gathered}
$$

\section{Kinetic Studies}

The kinetic studies were conducted to estimate the contact time required for the attainment of equilibrium between the dissolved and solid bound adsorbate. This set of experiments were carried out by agitating with $100 \mathrm{~mL}$ of metal solutions whose concentrations were 50,100,150 and $200 \mathrm{mg} / \mathrm{L}$ at the optimum $\mathrm{pH}$ with $1.0 \mathrm{~g} / \mathrm{L}$ of PPHW in a shaker operated at room temperature. In order to identify the adsorption mechanism, the rate constants for chemisorption and intra-particle diffusion for mercury were determined using the models for pseudo-second-order [11] and intra-particle diffusion model [12].The pseudo-second-order kinetic model is expressed as:

$$
\frac{t}{q_{t}}=\frac{1}{k_{2} q_{1}^{2}}+\frac{1}{q_{1}} t
$$

where $q_{1}(\mathrm{mg} / \mathrm{g})$ is the maximum adsorption capacity and $q_{t}$ $(\mathrm{mg} / \mathrm{g})$ is the amount of metal adsorbed at time, $t$, and $k_{2}(\mathrm{~g} /$ ( $\mathrm{mg} \min )$ ) is the equilibrium rate constant for pseudo-second order adsorption.

The intra-particle diffusion kinetic model is expressed as:

$$
q_{t}=k_{t} t^{1 / 2}+C
$$

where $k_{t}\left(\mathrm{mg} /\left(\mathrm{g} \mathrm{min}{ }^{1 / 2}\right)\right)$ is the intra-particle diffusion rate constant and $C(\mathrm{mg} / \mathrm{g})$ is a constant that is related to boundary layer thickness.

\section{Determination of Activation Energy}

The thermodynamic parameters reflect the feasibility and spontaneous nature of the adsorption process. Arrhenius equation Eq. (5) represents the effect of temperature on rate constant and is represented as:

$$
\ln k=\ln A-\frac{E_{a}}{R T}
$$

where $k$ is the rate constant obtained with the best fit kinetic model (at different temperatures), $E_{a},(\mathrm{~kJ} / \mathrm{mol})$ is the activation energy, $A(\mathrm{~g} /(\mathrm{mg} \mathrm{min}))$, is the Arrhenius factor, $R$, is the gas constant and $T(K)$ is the solution temperature.

\section{RESUlTS AND DISCUSSION}

\section{A. Effect of $p H$}

Metal speciation is a vital phenomenon occurring during the adsorption of metal on sorbent surface. $\mathrm{pH}$ is reported to be influencing metal speciation and dissociation of active functional sites on the sorbent. The effect of $\mathrm{pH}$ on the adsorption of $\mathrm{Hg}$ by PPHW was studied by varying the $\mathrm{pH}$ of the metal solution from 3.0 to 9.0 under constant experimental conditions (initial metal concentration $=100$ $\mathrm{mg} / \mathrm{L}$, sorbent dosage $=1 \mathrm{~g} / \mathrm{L}$, a contact time $90 \mathrm{~min}$ and temperature $30^{\circ} \mathrm{C}$ ). Fig. 1 shows the dependence of removal efficiency of free ionic $\mathrm{Hg}$ on $\mathrm{pH}$. It can be observed from the figure that the removal of $\mathrm{Hg}$ (II) increases with increase in $\mathrm{pH}$ from 28 to $92 \%$ over $\mathrm{pH}$ range from 3.0 to 9.0. This increase in $\mathrm{pH}$ may be due to the presence of negative charge on the surface of the adsorbent that may be responsible for metal binding [13]. Decreased removal efficiencies at lower $\mathrm{pH}$ is due to the hydrogen ions competition with the metal ions for the sorption sites in the sorbent. This behaviour can also be related to the pHzpc value of PPHW which was estimated as 4.8 according to procedure given [14]. When the solution $\mathrm{pH}$ is less than $\mathrm{pHzpc}$, the surface is positively charged and the sorption of cationic metal will be less. But, when the $\mathrm{pH}$ is more than $\mathrm{pHzpc}$, the surface charges become more negative favouring better interaction with the metal [10]. The optimal $\mathrm{pH}$ was found to be 7.0. Similar observations were reported on the studies on removal of $\mathrm{Cu}$ on PHW [13].



Fig. 1. Effect of initial $\mathrm{pH}$ of the solution on the sorption of Mercury by PPHW ( $t=90 \mathrm{~min} ; C_{0}=100 \mathrm{mg} / \mathrm{L}, M=1.0 \mathrm{~g} / \mathrm{L}$ and $T=30^{\circ} \mathrm{C}$ ).

\section{B. Effect of Sorbent Dose}

The effect of sorbent dose on the adsorption of $\mathrm{Hg}$ (II) by PPHW was studied with the range of the adsorbent from 1.0 to $7.0 \mathrm{~g} / \mathrm{L}$ with initial metal concentration of $100 \mathrm{mg} / \mathrm{L}$ and optimal $\mathrm{pH}$ 7.0. The percentage removal of $\mathrm{Hg}$ (II) versus adsorbent dosage was shown in Fig. 2. It can be observed from the figure that the removal of $\mathrm{Hg}$ (II) increase with increase the dosage from 10 to $94 \%$ over dosage range 0.1 to $0.7 \mathrm{~g}$. This finding shows that $7.0 \mathrm{~g} / \mathrm{L}$ of adsorbent has enough 
exchangeable sites to remove the ions [13]. The phenomenon of increasing removal of $\mathrm{Hg}$ (II) with increase in adsorbent dose may be explained as with increase in adsorbent dose, more and more surface area become available for metal ion to adsorb and this increased the removal efficiency [15]. But the adsorbent dosage was found to have negative effect on $\mathrm{Hg}$ (II) uptake, which decreases with increase in sorbent dosage in the same range. It was observed that the uptake of $\mathrm{Hg}$ (II) decreased with the increase in the adsorbent dosage as shown in Fig. 3. Similar observations were reported in other studies [13], [16], [17].



Fig. 2. Effect of sorbent dosage on percentage removal and metal uptake for the sorption of Mercury by PPHW ( $t=90 \mathrm{~min}, C_{0}=100 \mathrm{mg} / \mathrm{L}, \mathrm{pH}=7$ and $\left.T=30^{\circ} \mathrm{C}\right)$.

\section{Effect of Initial Metal Concentration}

The influence of $\mathrm{Hg}^{+2}$ concentrations on the sorption by the AAPHW was investigated by varying the $\mathrm{Hg}^{+2}$ concentrations from 50 to $200 \mathrm{mg} / \mathrm{L}$ at $\mathrm{pH} 7.0$ for $90 \mathrm{~min}$ equilibrium time. From the Fig. 3, it was evident that the metal uptake increased with the increase in $C_{0}$. Overall, the rate of Mercury uptake was higher with in first 30 min contact time [18]. But, the removal percentages decreased with increase in metal concentrations. The increase of initial $\mathrm{Hg}^{+2}$ concentrations resulted in a reduction of its adsorption percentage due to limited adsorption sites ratio of metal to PPHW [16].

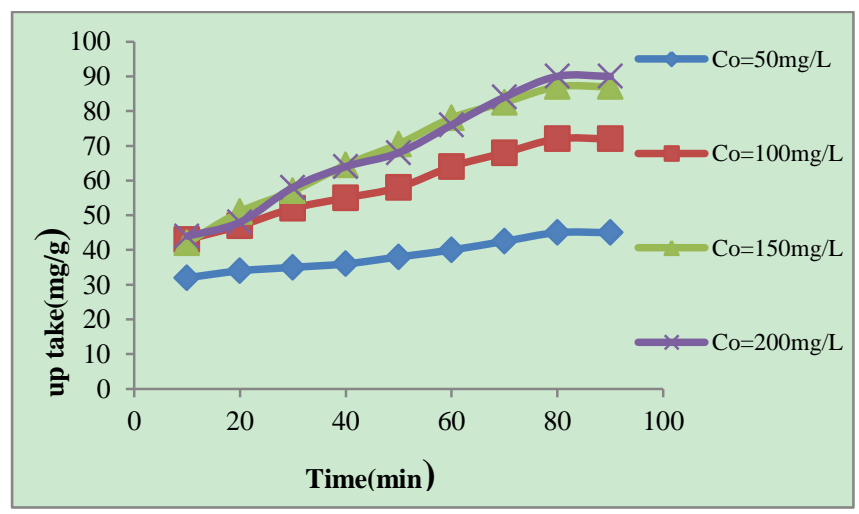

Fig. 3. Effect of initial metal concentration on uptake $(t=90 \mathrm{~min} ; M=1.0 \mathrm{~g} / \mathrm{L}$, $\left.\mathrm{pH}=7, T=30^{\circ} \mathrm{C}\right)$.

\section{Effect of Temperature}

The effect of temperature on the removal of mercury was studied in the range of $303-323 \mathrm{~K}$ at optimal $\mathrm{pH} 7$, initial metal concentration $100 \mathrm{mg} / \mathrm{L}$ and sorbent dosage $1.0 \mathrm{~g} / \mathrm{L}$. The equilibrium sorption capacity of mercury increased with increase in temperature and was shown in Fig. 4. Thus, the sorption process was identified as endothermic in nature [10]. Since adsorbent is porous and possibilities of diffusion adsorbate cannot be ruled out, increase in the sorption with the rise of temperature may be diffusion controlled which is endothermic process [13]-[15]. Other researcher [10] also observed similar temperature effects on metal sorption studies. But, the magnitude of the effect was found to be different among these studies.

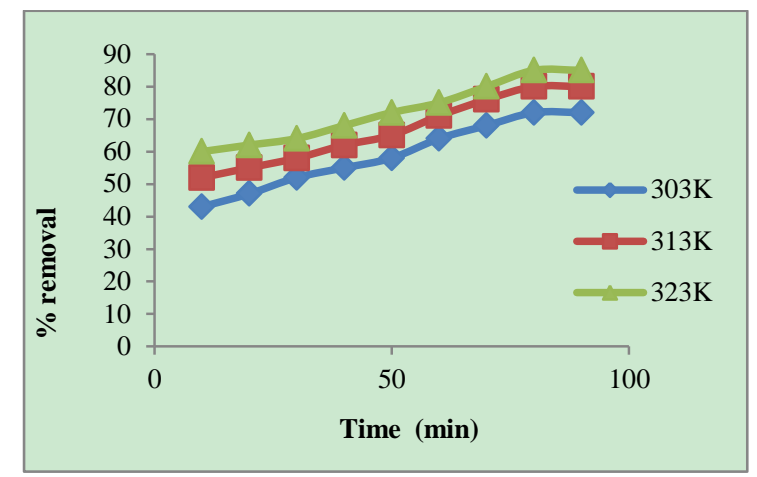

Fig. 4. Effect of temperature on metal removal for the sorption of mercury by AAPHW ( $t=90 \mathrm{~min}, \mathrm{pH}=7, C_{0}=100 \mathrm{mg} / \mathrm{L}$ and $\left.M=1 \mathrm{~g} / \mathrm{L}\right)$.

\begin{tabular}{|l|c|c|c|c|}
\hline TABLE I: KINETIC MODEL CONSTANTS \\
\hline Kinetic model & \multicolumn{4}{|c|}{ Initial metal concentration(mg/L) } \\
\hline & 50 & 100 & 150 & 200 \\
\hline $\begin{array}{l}\text { Pseudo second order } \\
k_{2}\left(\mathrm{~g} \mathrm{mg}^{-1} \mathrm{~min}^{-1}\right) \\
\times 10^{3}\end{array}$ & 1.99 & 0.77 & 0.412 & 0.34 \\
\hline$q_{1}\left(\mathrm{mg} \mathrm{g}^{-1}\right)$ & 48.78 & 82.64 & 107.5 & 113.64 \\
\hline$R^{2}$ & 0.976 & 0.992 & 0.989 & 0.99 \\
\hline $\begin{array}{l}\text { Intraparticle } \\
\text { diffusion }\end{array}$ & & & & \\
\hline$k_{t}\left(\mathrm{mg} \mathrm{g} \mathrm{min}^{-1 / 2}\right)$ & 2.2 & 4.9 & 7.67 & 8.4 \\
\hline$C$ & 23.07 & 25.19 & 29.67 & 31.73 \\
\hline$R^{2}$ & 0.944 & 0.978 & 0.969 & 0.976 \\
\hline
\end{tabular}

\section{E. Kinetic Studies}

The transient behaviour of the metal adsorption process was studied through kinetic experiments and analysed using pseudo-second-order and intra-particle diffusion model. The values of $k_{2}$ at different initial metal concentrations for all adsorbents were calculated from the slopes of the respective linear plots of $t / q_{t}$ vs. $t$. Fig. 5 show Pseudo-second-order kinetic plots for the sorption of Mercury on PPHW at 303, 313 and $323 \mathrm{~K}$. The fitness of experimental data to pseudo-second order model implies that adsorption is likely controlled by chemisorptions, including the sharing or exchanging of electrons between metal ion and adsorbent [10], [19]. The correlation coefficient was found to be $>0.97$, suggesting a strong relationship between the parameters and also explains that the process follows pseudo-second-order kinetics. A plot of $q_{t}$ vs. $t^{1 / 2}$ was made to test the intra-particle diffusion as shown in Fig. 6; if it passes through origin, intra-particle diffusion is the only rate controlling step [20] .This possibility was tested in terms of a graphical relationship between the amount of metal adsorbed and square root of time at different initial metal concentration. All the plots have the same general aspect. They all have an initial curved portion, followed by an intermediate linear portion. The initial portion of these plots is related to mass transfer and the linear part is due to intra-particle diffusion. Previous studies showed the same features of the plots of $q_{t}$ 
vs. $t^{1 / 2}$ which characterize the different steps of adsorption process [19], [21]. The values of rate constant for intra-particle diffusion, $\left(k_{t}\right)$ at different initial metal concentration for all adsorbents was determined from the slopes of the linear portions of the respective plots and were given in Table I. The results revealed that the $R^{2}$ was greater for pseudo second order model compared to the other.

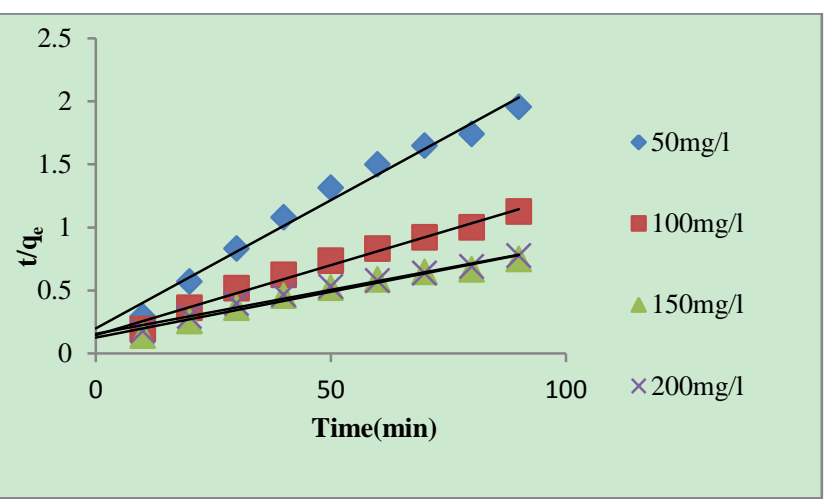

Fig. 5. Pseudo-second-order model for the sorption of Mercury on PPHW.

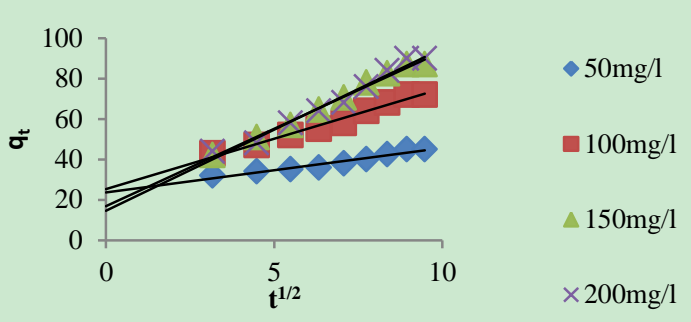

Fig. 6. Intra particle diffusion model for the sorption of Mercury on PPHW.

\section{F. Thermodynamic Studies}

The thermodynamic parameters reflect the feasibility and spontaneous nature of the adsorption process. The rate constant from the best fit model, pseudo-second-order kinetic model. $K_{2}$ was chosen to plot of $\ln k_{2}$ versus $1 / T$ and shown in Fig. 7. The slope of the best fit line revealed the Activation energy $\left(E_{a}\right)$ of the biosorption process to be $10.26 \mathrm{KJ} / \mathrm{mol}$ with PPHW. This fact is consistent with the properties of the adsorbent and Langmuir-type adsorption isotherm.



Fig. 7. Arrhenius plot.

\section{CONCLUSIONS}

Protonated pistachio hull waste has been proved as a potential sorbent for the removal of mercury from its aqueous solution. Effect of operating parameters, such as $\mathrm{pH}$, sorbent dosage, initial metal concentration and temperature, on the metal removal efficiency were studied. The optimal $\mathrm{pH}$ was found to be 7.0 and adsorbent dose was found to be $1.0 \mathrm{~g} / \mathrm{L}$. The sorption process was identified as endothermic in nature. Two different kinetics models (pseudo-second-order and intra-particle diffusion) were studied to analyse the transient behaviour of the metal adsorption process. Pseudo-second-order model was the best model representing the adsorption of $\mathrm{Hg}^{+2}$. From thermodynamic studies, activation energy for the adsorption of was found to be 10.26 $\mathrm{kJ} / \mathrm{mol}$.

\section{ACKNOWLEDGEMENTS}

The author would like to thank Sohar University for providing the necessary facilities for conducting this study.

\section{REFERENCES}

[1] R. C. Bansal and M. Goyal, Activated Carbon Adsorption, Taylor and Francis Group, London, 2005.

[2] F. Fu and Q. Wang, "A review of Removal of heavy metal ions from wastewaters," Journal of Environmental Management, vol. 92, pp. 407-418, 2011.

[3] H. Hussein, S. F. Ibrahim, K. Kandeel, and H. Moawad, "Biosorption of heavy metals from waste water using Pseudomonas sp," Electronic Journal of Biotechnology, vol. 7, issue 1, pp. 30-37, 2004.

[4] S. A. Mirbagheri and S. N. Hosseini, "Pilot plant investigation on petrochemical wastewater treatment for the removal of copper and chromium with the objective of reuse," Desalination, vol. 171, pp. 85-93, 2005.

[5] B. Alyüz and S. Veli, "Kinetics and equilibrium studies for the removal of mercury and zinc from aqueous solutions by ion exchange resins," $J$. Hazard. Mater., vol. 167, pp. 482-488, 2009.

[6] C. Brachpapa, B. Coulomb, J. L. Boudenne, V. Cerda, and F. Theraulaz, "Recovery of metals from complexed solution by electrodeposition," Anal. Chem. Acta., vol. 457, pp.311-318, 2002.

[7] W. S. Wan Nagh and M. A. K. M. Hanafiah, "Removal of heavy metal ions from wastewater by chemically modified plant wastes as adsorbents: A review," Bio resource Technology, vol. 99, pp. 3935-3948, 2008.

[8] M. N. Khan and M. F. Wahab, "Characterization of chemically modified corncobs and its application in the removal of metal ions from aqueous solution," J. Hazard. Mater., vol. 141, pp. 237-244, 2006.

[9] D. Ozer and A. Ozer, "The adsorption of copper (II) ions onto dehydrated wheat bran (DWB): determination of equilibrium and thermodynamic parameters," Process Biochem., vol. 39, pp. 2183-2191, 2004.

[10] G. Moussavi and B. Barikbin, "Biosorption of chromium (VI) from industrial wastewater onto pistachio hull waste biomass," Chemical Engineering Journal, vol. 162, pp. 893- 900, 2010.

[11] Y. S. Ho and G. Mckay, "The kinetics of sorption of divalent metal ions onto sphagnum moos peat," Water Res., vol. 34, issue 3, pp. 735-742, 2000.

[12] W. J. Weber and J. C. Morris, Proceedings of the International Conference on Water Pollution Symposium, vol. 2, Pergamon Press, Oxford, 1962.

[13] M. Kazemipour, M. Ansari, S. Tajrobehkar, M. Majdzadeh and H. R. Kermani, "Removal of lead, cadmium, zinc, and copper from industrial wastewater by carbon developed from walnut, hazelnut, almond, pistachio shell, and apricot stone," Journal of Hazardous Materials., vol. 150, pp. 322-327, 2008,

[14] G. Moussavi and M. Mahmoudi, "Removal of azo and anthraquinone reactive dyes from industrial waste waters using $\mathrm{MgO}$ nanoparticles," $J$. Hazard. Mater, vol. 168, pp. 806 -812, 2009,

[15] E. I. El-Shafey, "Behavior of reduction - sorption of chromium (VI) from an aqueous solution on a modified sorbent from Rice Husk," Water air and soil poll., vol. 163, pp. 81-102, 2005.

[16] G. Moussavi and R. Khosravi, "The removal of cationic dyes from aqueous solutions by adsorption onto pistachio hull waste," Chemical Engineering Research and Design, vol. 89, pp. 2182- 2189, 2011.

[17] N. Thinakaran, P. Panneerselvam, P. Baskaralingam, D. Elango, and S. Sivanesan, "Equilibrium and kinetic studies on the removal of Acid Red 114 from aqueous solution using activated carbons prepared from seed shells," J. Hazard. Mater. vol. 158, pp. 142-150, 2008.

[18] S. Mathpal, and N. D. Kandpal, "Colorimetric estimation of Ni (II) ions in aqueous solution," E-Journal of Chemistry, vol. 6, issue 2, pp. 445-448, 2009. 
[19] X. S. Wang, L. F. Chen, F. Y. Li, K. L. Chen, W. Y. Wan, and Y. J. Tang, "Removal of chromium (VI) with wheat - residue derived black carbon: reaction mechanism and adsorption performance," $J$. Hazard.Mater., vol. 175, pp. 816-822, 2010.

[20] I. A. Aguayo-Villarreal, A. Bonilla-Petriciolet, V. A. Hernández-Montoya, M. E. Montes-Moránc, and H. Reynel-Avila, "Batch and column studies of $\mathrm{Zn}^{2+}$ removal from aqueous solution using chicken feathers as sorbents," Chemical Engineering Journal, vol.167, pp. 67-76, 2011.

[21] N. K. Amin, "Removal of reactive dye from aqueous solutions by adsorption onto activated carbons prepared from sugarcane bagasse pith," Desalination, vol. 223, pp. 152-161, 2008.

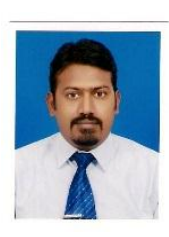

Rajamohan Natarajan holds a doctoral degree in chemical engineering and has been working as a professor in chemical engineering, Faculty of Engineering, Sohar University, Oman. He has more than 15 years of teaching and research experience. He has completed three funded research projects and presently carrying out two in the fields of biofiltration, bioremediation of heavy metals and novel effluent treatment technologies. To his credit, he has published 42 papers in various reputed international journals. He is a member of various professional bodies and editorial board of peer reviewed journals. He has won "Outstanding young Chemical Engineer Award" instituted by IIChe. 